$\infty$

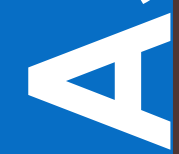

17

C

II

02 




\section{Reseña. Cuerpo siamés, Paulina León y María Dolores Ortiz. Turbina, Quito, 2017}

\section{Review. Cuerpo siamés, Paulina León and MaríaDolores Ortiz. Turbina, Quito, 2017}

\section{Daniela Alcívar Bellolio}

ISSN (imp): 1390-4825

ISSN (e): 2477-9199
Fecha de recepción: 03/04/18 Fecha de aceptación: 10/05/18

\section{Resumen:}

La reseña procura presentar el libro-objeto colectivo Cuerpo siamés, editado por Turbina en 2017, alrededor del trabajo de La dupla, intervención artística de Paulina León y María Dolores Ortiz. A través del dispositivo del cuerpo doble, que las artistas representan en ámbitos diversos, varios autores e investigadores exploran los alcances del cuerpo, los límites de las leyes y de la medicina, y ensayan nuevas formas de ver y pensar todas aquellas formas apartadas de la norma.

\section{Palabras clave:}

Cuerpo, siamés, norma, intervención, ley, medicina, enfermedad

\section{Abstract:}

This review present Cuerpo Siamés, a collective book-object edited in 2017by Turbina. This book revolves around the artistic work of La Dupla, artistic intervention by Paulina León and María Dolores Ortiz. Through the twinbody device, which is represented by the artists in various scenes, a number of authors and investigators explore the extent and potency of the body and the limits of Law and Medicine, and test new ways of seeing and thinking shapes and bodies that are set apart from the norm.

\section{Key Words:}

Body, siamese, norm, intervention, law, medicine, illness.

\section{Biografía de la Autora:}

Daniela Alcívar Bellolio (Guayaquil, 1982). Candidata a doctora por la Facultad de Filosofía y Letras de la Universidad de Buenos Aires, becaria doctoral de CONICET y del Instituto de Literatura Hispanoamericana (ILH-UBA, Argentina). Becaria del Fondo Nacional de las Artes (FNA-, de Argentina). Investiga las modulaciones del paisaje y la imagen como dispositivos narrativos en la obra de escritores argentinos y latinoamericanos de los siglos XX y XXI. Ha publicado artículos académicos en revistas especializadas de Argentina, Colombia, España, Alemania, Italia, Estados Unidos y Ecuador. Es autora de los libros de ensayos Pararrayos. Paisajes, lecturas, memorias (Turbina, 2016) y El silencio de las imágenes (La caracola, 2017). Código ORCID: https://orcid.org/0000-0002-7829-3312 


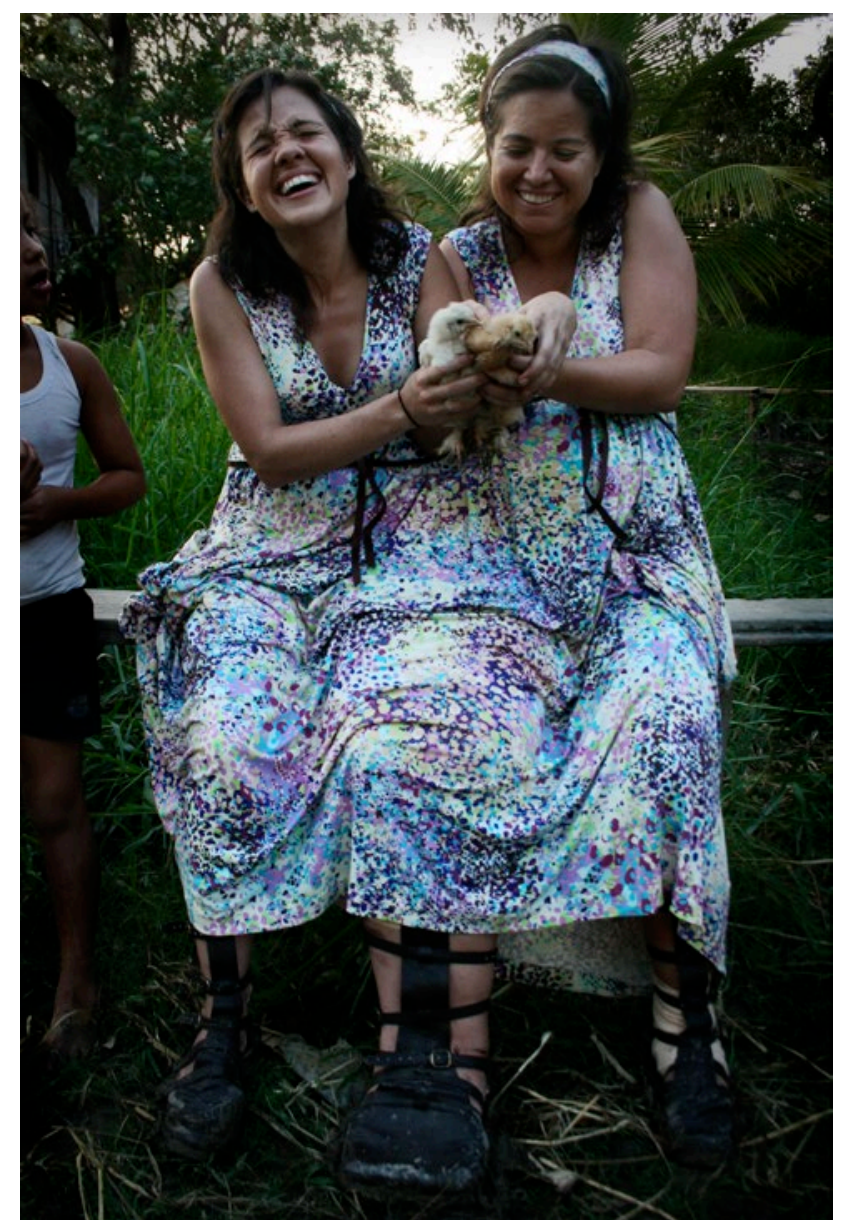

2. Performance La dupla en Santay, 2010.

Fotografía: Pedro Cagigal

goza y conversa, los presupuestos más naturalizados de lo que son un cuerpo y un individuo. Estas preguntas sobre el ser del cuerpo y la constitución de la identidad individual generadas por Leo y Lu decantan de lo ontológico a la potencia en el ensayo de María del Pilar Gavilanes, partiendo de la pregunta fundacional de la Ética de Spinoza: ¿qué puede un cuerpo? Del ser a la potencia: el agenciamiento de las hermanas siamesas produce formas nuevas de lo común, de la convivencia, que por la vía del deslizamiento (y no de la metáfora), despliegan imágenes de lo plural que impugnan las nociones identitarias convencionales. " $\mathrm{La}$ dupla escribe Gavilanes- plantea la posibilidad de pensar y de actuar desde el plural. Ponerse de acuerdo, asociar voluntades, acordar esfuerzos, potencializar capacidades son operaciones que determinan las formas de nuestros cuerpos [...]. El estar en el mundo se entiende entonces como un potencial, a partir de las acciones, los afectos y las pasiones que puede soportar y desarrollar un cuerpo desde su singularidad" (2017, s/n).

Algunos ensayos del libro exploran, en este sentido también, la ambigüedad que propone y pone en acto el dispositivo del cuerpo siamés: ¿qué hace al sujeto? ¿Está el individuo en el cerebro? ¿Un cuerpo con dos cabezas son dos personas? Una cabeza con cuatro brazos y cuatro piernas, ¿cuántas personas son? Karina Marín, por ejemplo, se plantea nuevamente la cuestión cartesiana (cogito ergo sum) para desarmar sus consecuencias en el cuerpo extraño de Leo y Lu: "Aunque se instituyera la centralidad absoluta del cerebro, ¿cómo compaginar esta relación cuando dos órganos hegemónicos 'mandan', por decirlo de algún modo, sobre un solo cuerpo? Esa es, entonces, la circunstancia extrema a la que estamos avocados cuando pensamos/ miramos un cuerpo bicéfalo" (2017, s/n).

La naturalizada unidad del Yo y el cerebro se pone en cuestión en la existencia de los hermanos siameses en la medida en que ellos abren una grieta en la continuidad que esa unidad plantea: dos cerebros mandando sobre un mismo cuerpo rompen el dispositivo, lo extrañan, lo bifurcan. Entonces, no sabemos bien si Leo y Lu son dos (cada una tiene su personalidad, su temperamento, sus propias e intransferibles inclinaciones), si son una (la noción de privacidad en el cuerpo siamés muta radicalmente $-\mathrm{y}$ es una de las inquietudes más frecuentes en las personas con las que dialogan en Jambelí e Isabela-, la preeminencia de la autonomía de Yo es puesta en cuestión) o si son, finalmente, otra cosa, algo más que comparte fluidos, órganos vitales, una pierna central.

En ese sentido, Cristina Burneo Salazar reflexiona sobre lo que implica "descender al cuerpo":

Para aproximarse al cuerpo hay que descender al cuerpo. Digo que descendemos al cuerpo porque pensarlo es una tarea baja: sus órganos, fluidos, tubos, orificios, funciones han sido reprimidos por siglos y aun suprimidos en nombre del alma, la mente, el espíritu (2017, s/n).

Para Burneo, Leo y Lu (y todo cuerpo siamés, todo cuerpo apartado de la norma, todo cuerpo que interpela los presupuestos que se lo figuran como un recipiente de racionalidad o espíritu) inquietan y desvían, irradian sentidos y afectos hacia otros cuerpos, hacia cuerpos otros. Por eso rompen con la unidad que el concepto supone: si el concepto unifica, en una imagen convencional, la generalidad dispersa de los objetos del mundo, para poder ser comunicada y comprendida de modo eficiente, 


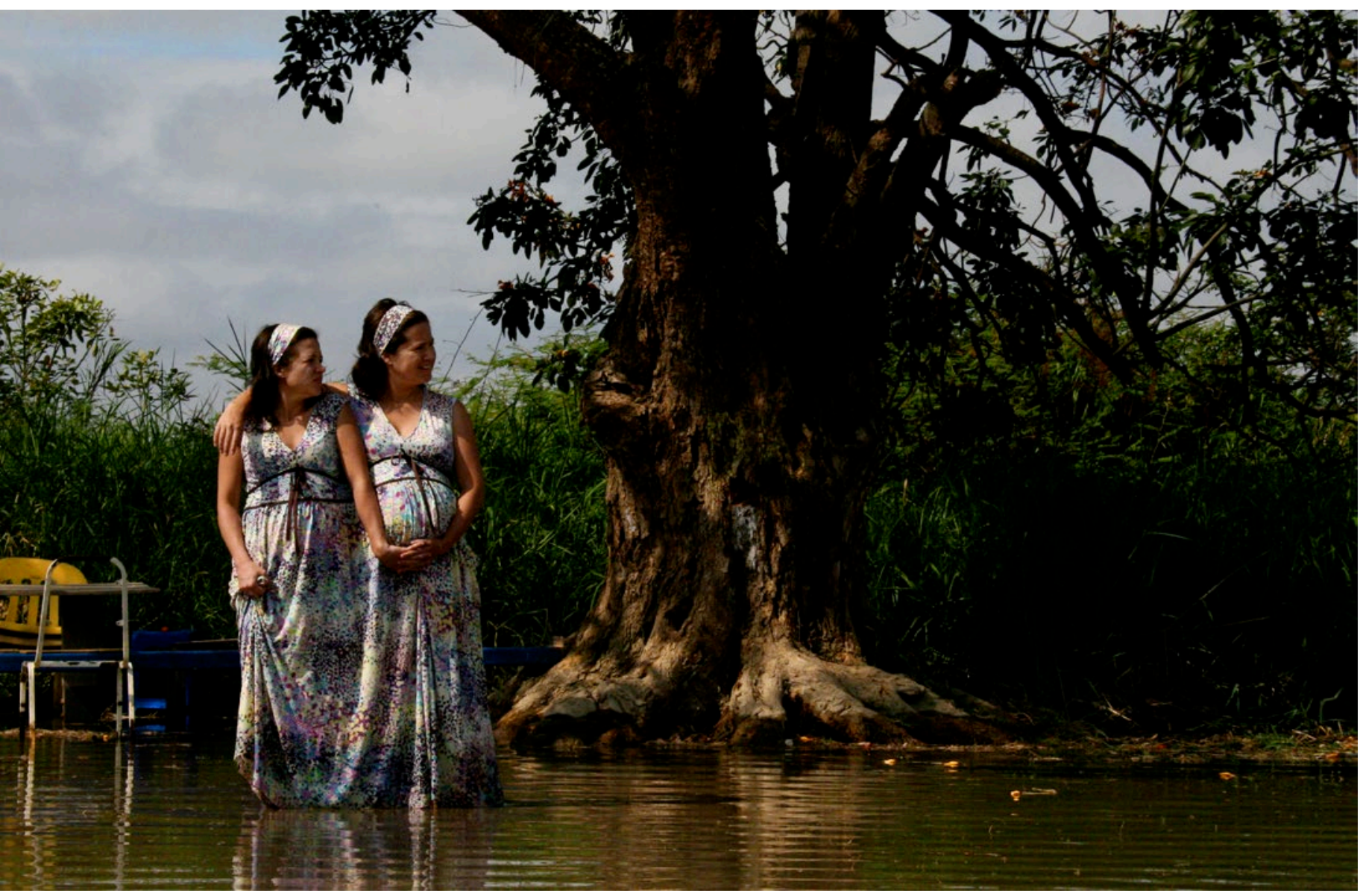

3. Performance La dupla en Santay, 2010. Fotografía: Pedro Cagigal

el cuerpo siamés, todo aquello que abarca e implica un cuerpo geminado (Burneo), lleva a cabo una operación contraria, toma la unidad y la dispersa, la hace inaprensible, impensable, fluida, abierta, radicalmente no-única.

Por eso, con Cuerpo siamés la impresión no es precisamente la de algo duplicado: se trata más bien de algo abierto e impreciso, esencialmente sin esencia, ambiguo. El concepto editorial es claro y bien ejecutado: el libro puede leerse por los dos lados, se insiste en figuras e imágenes que expresan una duplicidad simétrica, como las mariposas, por ejemplo, o los troquelados interiores que se encuentran justo en el vértice del encuadernado. Se trata efectivamente de un libro-objeto que hace suyo, apostando por las formas de lo conceptual, esa duplicidad en acto de lo siamés. Y sin embargo, hay algo en las imágenes que el libro desarrolla desde los ensayos, los diálogos de las artistas con los habitantes de las islas y, en general, desde sus postulados fundamentales, que impugna la idea de la simple duplicación. Aquí no hay algo que se repite. Aquí el cuerpo prolifera.

Fausto Rivera Yánez trabaja en su ensayo esta noción de lo abierto en articulación con lo vero- símil. Las preguntas giran alrededor de los conceptos de normalidad y verosimilitud aplicados a los cuerpos. Rivera traslada el bello sintagma que Foucault enunciara para hablar del cuerpo utópico, "topía despiadada", para desarmar los estereotipos culturales que norman lo que puede y lo que no puede ser a espaldas de la ineluctable materialidad existente de los cuerpos que contradicen esos mandatos. Topía: espacio afirmado, espacio verdadero, habitado. Cuerpo como extensión fehaciente, indudable. La idea es afirmar la existencia y, por consiguiente, la potencia de estos cuerpos para abrirse espacio en el mundo y generar sus propios paisajes, sus propios artefactos, sus propias y singulares formas de ser. Si un cuerpo ocupa un espacio, entonces es imposible negarlo. Dice Rivera Yánez hacia el final de su texto: "La dupla, esa 'topía despiadada', es una pregunta abierta en un mundo que exige respuestas cerradas. Es el cuerpo en el cual todos nos podemos reconocer, desde su precariedad y luminosidad. Es el cuerpo doble, verosímil, infinito. Es la posibilidad de pensarnos y devenirnos diferentes" (2017, s/n).

Cuerpo siamés articula, pues, una variedad de perspectivas, hace convivir el lenguaje biológico con el 
antropológico, el poético y el filosófico; la terminología técnica de los modos en que puede entenderse al cuerpo siamés desde el punto de vista de la teoría evolutiva (en el ensayo de Marcos Neira leemos sobre la conveniencia que, en términos evolutivos, podría tener un animal de dos cabezas) con la yuxtaposición literaria -la imagen duplicada- del cuerpo doble con las cuerdas vocales: la resonancia que genera una extrema cercanía con otro cuerpo (Cristina Mancero). María Fernanda Ugalde aporta una visión arqueológica al tema: en la existencia inmemorial de cuerpos geminados, imprecisos, entre lo zoo y lo antropomorfo, en la posible carga divina que estos cuerpos podrían haber llevado consigo en culturas como La Tolita (en la que se enfoca el texto de Ugalde), se juega una des-jerarquización de los saberes y la cosmovisión occidental a favor de una puesta en juego de otros modos de ver el mundo, alejados de lo binario y lo moral, tal como lo entendemos hoy, no para pretender la búsqueda de algún paraíso perdido, sino para volver a la certeza de que toda clasificación es una invención reductora.

En este sentido también, en el ensayo de Diego Falconí Trávez este deseo se pone en práctica en el ámbito jurídico, fundamental para repensar las relaciones de poder que se establecen entre la Ley como conjunto normativo que rige las sociedades y los seres vivientes, materiales, extensos y proliferantes que desafían esas verdades construidas para Occidente desde el Derecho Romano. Falconí cuestiona los engranajes de la Ley en su poder para normativizar los cuerpos y restar verosimilitud a las disidencias (y su articulación profunda con la Medicina), con el objetivo de postular una necesidad de protección y cuidado de los cuerpos vulnerables, de las vidas precarizadas; es decir, de la importancia de la potencia de indisciplina que la "monstruosidad siamesa" puede ejercer $(2017, \mathrm{~s} / \mathrm{n})$.

Y Pamela Jijón, desde la filosofía, explora las posibilidades del asocio que ofrece un cuerpo que desafía la continuidad entre subjetividad y percepción, planteada por la fenomenología para entender al sujeto: "Así, el cuerpo siamés, en su doble inmanencia en el mundo, nos permite pensar el cuerpo, no de manera estrictamente individual y sicológica, sino, desde una dimensión trascendental del ser (con mayúsculas) en el mundo. El cuerpo siamés es, en cierto sentido, el extremo de la intercorporeidad, en la que 'los paisajes del mundo se entrelazan” (2017, s/n).
Conviviendo con todas estas posturas, apuestas y preguntas, la clara y sonriente figura del cuerpo siamés: Leo y Lu con sus vestidos floreados hechos a mano. Leo y Lu desactivando las formas clásicas de explotación de la rareza desde el lenguaje publicitario, televisivo, cinematográfico a través de la ironía y el escepticismo. Leo y Lu fundiéndose en paisajes dispersos, que acentúan o recuerdan la belleza de lo informe. Leo y Lu hablando con la gente, con los niños, riéndose de sí mismas y de ellos, de sus preguntas indiscretas, planteando preguntas subversivas (“'YY cómo se siente la soledad?”), teniendo sexo, pariendo, criando, bebiendo. Leo y Lu caminando por islas como si recorrieran un paisaje que les corresponde, que las interpela y las abre a esa experiencia desconocida para ellas que es la soledad: "Ahora que conocimos las islas yo creo que nosotras, a donde vayamos, siempre vamos a ser como una isla. Rodeadas de una masa que tiene otras características. No somos la única isla, hay otras tantas, pero las islas nunca se topan” (2017, s/n).

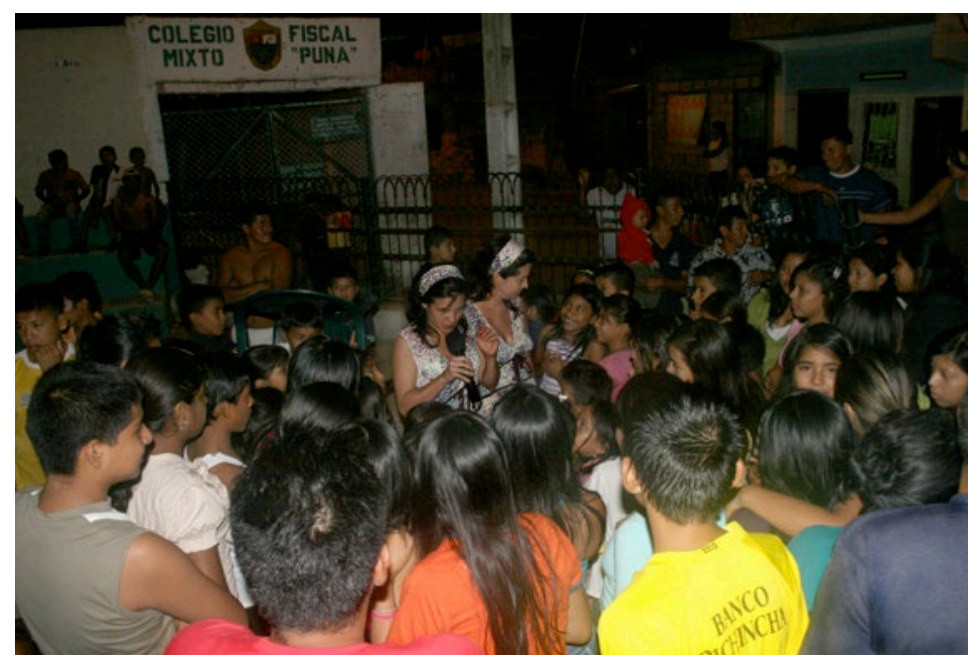

4. Performance La dupla en Puná, 2010.

Fotografía: Pedro Cagigal

Paulina León y María Dolores Ortiz crean continuamente (porque el proyecto de La dupla no deja de reimaginarse y rearmarse) formas nuevas de habitar ese cuerpo siamés que inventaron y de hacerle espacio en el mundo para que él también pueda habitar, extenderse, expandirse, abrirse. Cuerpo siamés, libro juguetón y bello, hecho para leer y para ver, para tocar, para oler y para explorar, hace de esa experiencia mutante una manifestación conceptual que, como todo lo que no abandona nunca su vocación de metamorfosis, rompe constantemente sus presupuestos e invita al lector a explorar su propia, íntima, ambigüedad. 


\section{BIBLIOGRAFÍA}

Burneo Salazar, C. (2017). Cuerpo geminado. En P. León y M. D. Ortiz, Cuerpo siamés (s/p), Quito, Ecuador: Turbina.

Díaz, B. (2017). Inquietaciones ante un cuerpo siamés (apuntes tras sumergirme en $\mathrm{La}$ dupla, personaje de Dolores Ortiz y Paulina León. En P. León y M. D. Ortiz, Cuerpo siamés (s/p), Quito:, Ecuador Turbina.

Falconí Trávez, D. (2017). De leyes, disciplina y metáforas siamesas. En P. León y $\mathrm{M}$. D. Ortiz, Cuerpo siamés (s/p), Quito, Ecuador: Turbina.

Gavilanes, M. P. (2017). Lo que puede un cuerpo. En P. León y M. D. Ortiz, Cuerpo siamés (s/p), Quito, Ecuador: Turbina.

Jijón, P. (2017). El lazo entre el cuerpo propio y el cuerpo asociado. En P. León y M. D. Ortiz, Cuerpo siamés (s/p), Quito, Ecuador: Turbina.

Mancero, C. (2017). Cuando se montan numeritos. En P. León y M. D. Ortiz, Cuerpo siamés (s/p), Quito, Ecuador: Turbina.

Marín, K. (2017). Dos cerebros. En P. León y M. D. Ortiz, Cuerpo siamés (s/p), Quito, Ecuador: Turbina.

Neira, M. (2017). Organismos siameses, ¿uno o dos individuos?. En P. León y M. D. Ortiz, Cuerpo siamés (s/p), Quito, Ecuador: Turbina.

Rivera Yánez, F. (2017). La dupla: experimentar el cuerpo plural y abierto. En P. León y M. D. Ortiz, Cuerpo siamés (s/p), Quito, Ecuador: Turbina.

Ugalde, M. F. (2017).¿En qué nos hacen pensar las representaciones iconográficas de siameses en el arte precolombino? Taxonomías contemporáneas enfrentadas a las cosmovisiones no-occidentales. En P. León y M. D. Ortiz, Cuerpo siamés (s/p), Quito, Ecuador: Turbina. 
INDEX \#05 